\title{
Dynamics of Vehicles Equipped with Traffic Lane Change Control System to Avoid Road Accidents
}

\author{
Daniel Sava $^{1}$, Ion Copae \\ Eng., S.A-R City Insurance, Bucharest, Romania1 \\ Professor eng. PhD, Department of Military Vehicles and Transportation, Military Technical Academy "Ferdinand I", \\ Bucharest, Romania2
}

\begin{abstract}
The paper presents some theoretical elements related to the traffic lane storage system, as well as the modeling-simulation of the operation of this system. The mathematical model is presented and results are obtained using the Matlab program and the Simulink toolbox. The double lane change is also addressed, which is the route to verify the operation of the ISO 3888-2 certified electronic stability control system.
\end{abstract}

Keywords: traffic lane change, electronic control, road accidents, double lane change, keeping the lane.

\section{INTRODUCTION}

Changing the lane is a relatively complicated process, especially in congested traffic. Improper operation of the driver while changing lanes can cause serious, sometimes multiple road accidents $[2,3,4,5,6,9,16]$. Traffic safety is affected by the type, position, speed, acceleration and deceleration of existing vehicles on the current lane and the one desired by the driver.

In order to ensure safe driving while changing lanes and thus avoid road accidents, the associated control system, which assists the driver in driving, must calculate the appropriate distances, make decisions and warn the driver by comparison with the minimum safety distance. For this purpose, the vehicle must be equipped with different sensors, such as a $77 \mathrm{GHz}$ radar measuring up to a distance of $150 \mathrm{~m}$ and a CCD video camera measuring up to a distance of 60-70 $\mathrm{m} \mathrm{[14].}$

\section{ASSISTANCE SYSTEM FOR KEEPING TRAFFIC LANE}

The lane keeping assist system keeps the car's trajectory as close to the middle of the lane as possible by operating the steering $[13,15]$. The objective of the system is to keep close to the zero value both the deviation at the lateral distance $e_{1}$ and the deviation at the angle of rotation $e_{2}$ (fig. 1).

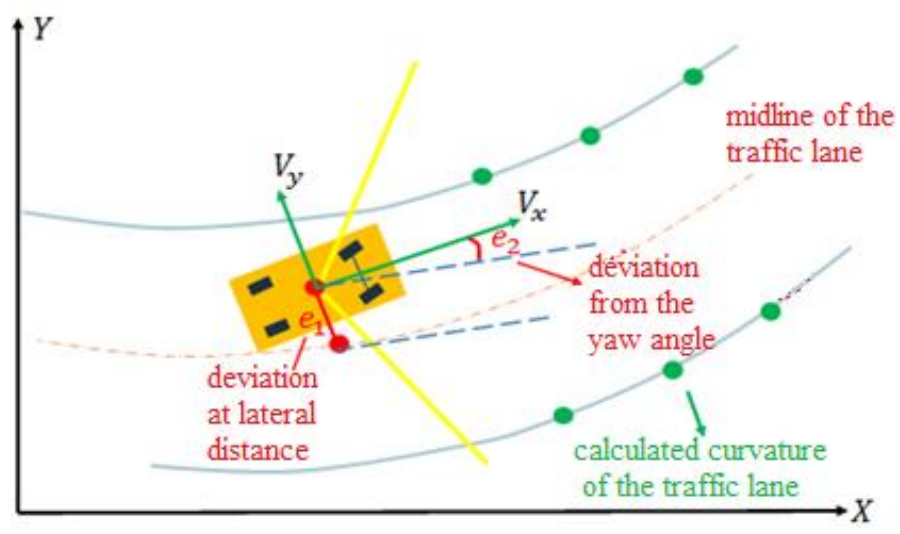

Fig. 1 Route plan and restrictions imposed on the lane keeping assistance system

The mathematical description of the model in the case of the unknowns $e_{1}$ and $e_{2}$ in fig. 1 is: 


\section{International Advanced Research Journal in Science, Engineering and Technology}

Vol. 8, Issue 4, April 2021

DOI: $10.17148 / I A R J S E T .2021 .8416$
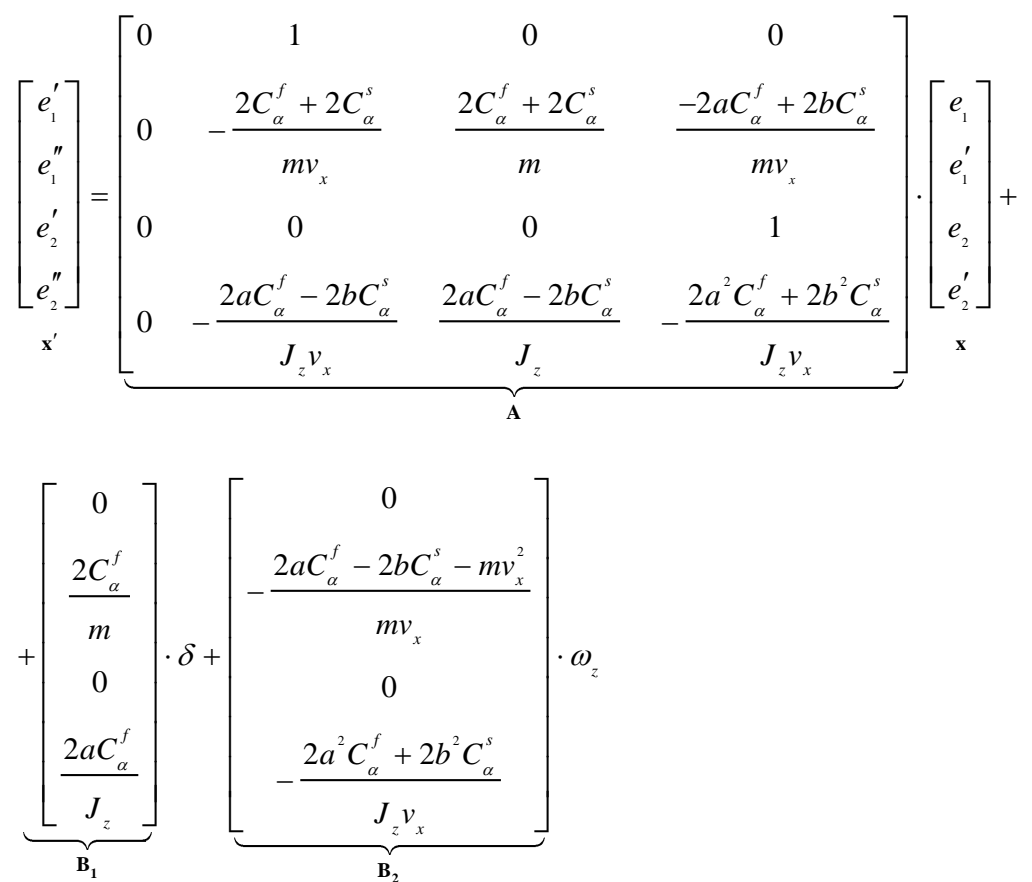

where the distance from the center of gravity to the front axle $a$ and to the rear axle $b$ is shown; the sum of the two distances is the wheelbase $A$. In addition, the following were noted: $J_{z}$ - the moment of inertia of the vehicle, $C_{\alpha}^{f}$ and $C_{\alpha}^{s}$ the lateral stiffness of a front and rear tire, $\delta$ - the steering angle of the wheel, which is influenced by the angle of rotation of the steering wheel $\delta_{v}, \omega_{z}$ - yaw rate, $m$ - mass of the vehicle, $v_{x}$ - longitudinal speed.

The lane keeping system uses, in this process, a camera that measures the deviation at the lateral distance and the relative deviation of the car's turning angle relative to the middle of the lane. The camera also measures the curvature of the lane; in plan, the curvature $\rho$ represents the inverse of the radius of curvature / turn $R$. The calculation of the curvature is performed using the trajectory theory for the double change of the traffic lanes. To simulate the operation of the lane keeping system, the Simulink model in fig. 2 is used, using the Matlab program.

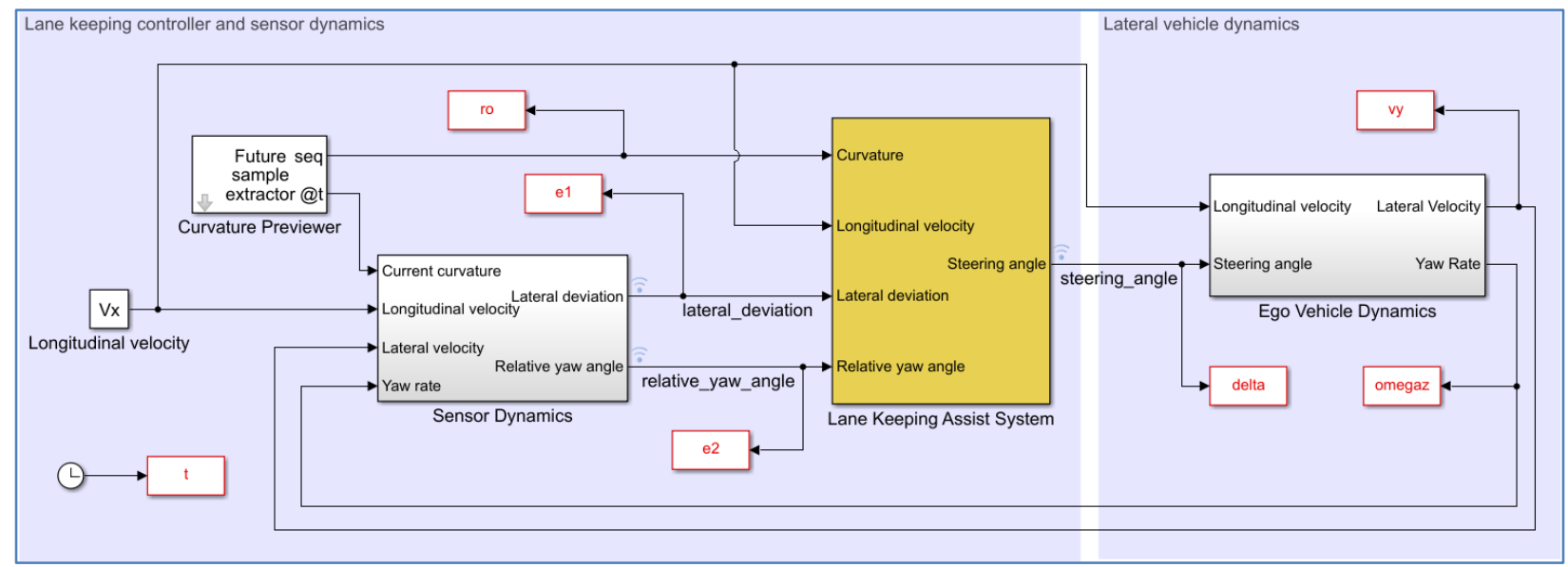

Fig. 2. Scheme for modeling and simulating the lane keeping assistance system [18]

The model on the axles, known in the literature as the bicycle model, is used to describe the lateral dynamics of the car. For this model, the longitudinal speed is considered constant, being the one imposed by the driver or by the traffic conditions in order to avoid collisions in the column $[12,18]$.

Fig. 3 and fig. 4 show the results obtained in the case of simulating lane keeping assistance at a longitudinal speed of $60 \mathrm{~km} / \mathrm{h}$ and a predictive control algorithm by model, in this case the mathematical model (1). 


\section{International Advanced Research Journal in Science, Engineering and Technology}

Vol. 8, Issue 4, April 2021

\section{DOI: $10.17148 / I A R J S E T .2021 .8416$}

Fig. $3 \mathrm{a}$ and fig. $3 \mathrm{~b}$ show that both the deviation at the lateral distance and the deviation at the yaw angle tend to zero, which means that the car keeps its trajectory, based on the calculated curvature (fig. 4d).

In addition, fig. $3 \mathrm{a}$ shows that the maximum deviations at the lateral distance are $26.4 \mathrm{~cm}$ on one side and 30.9 $\mathrm{cm}$ on the other side of the center line of the lane.

Fig. $3 \mathrm{~b}$ also shows that the maximum deviations of the yaw angle are 3.0 degrees (in trigonometric direction) and -4.6 degrees (clockwise), respectively.

Traffic lane keeping assistance system, predictive control by model, longitudinal speed $60 \mathrm{~km} / \mathrm{h}$

a) Deviation at lateral distance

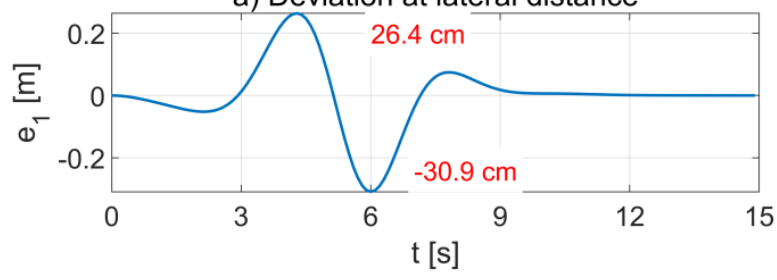

c) Wheel steering angle

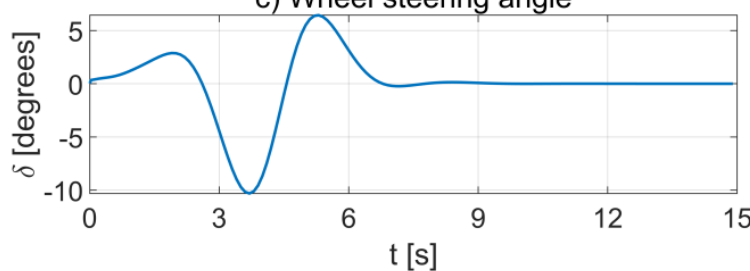

b) Deviation at the yaw angle

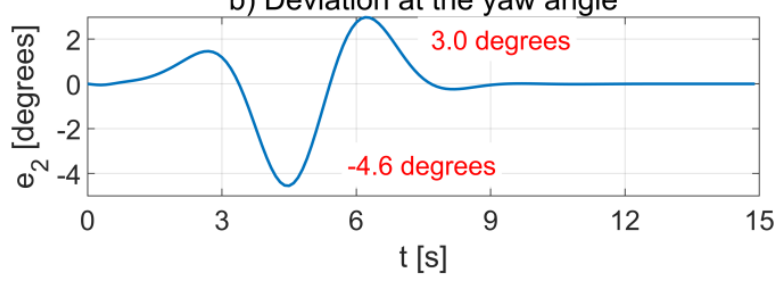

d) Lateral speed

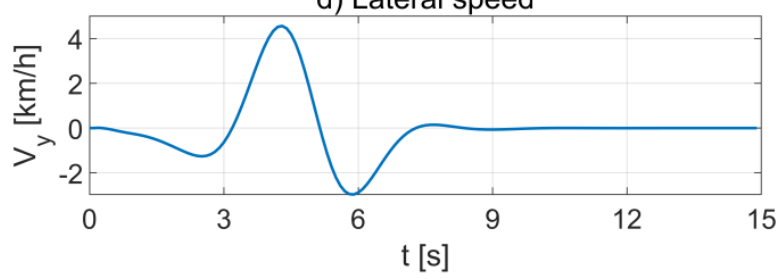

Fig. 3 Results obtained from the modeling of the lane keeping assistance system

Traffic lane keeping assistance system, predictive control by model, longitudinal speed $60 \mathrm{~km} / \mathrm{h}$

a) Lateral acceleration

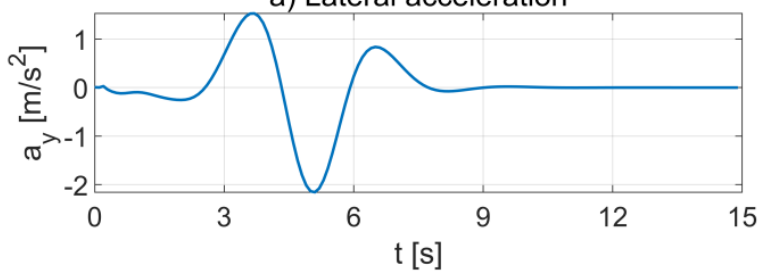

c) Yaw rate

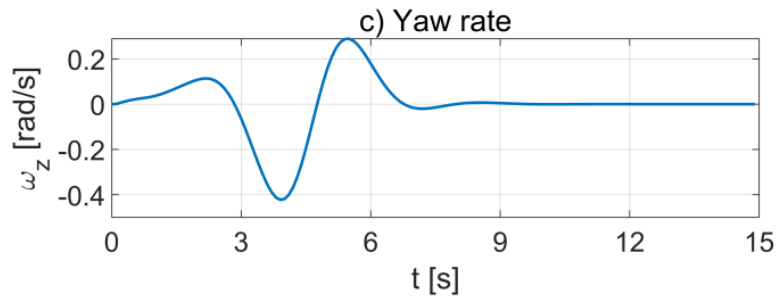

b) Yaw angle

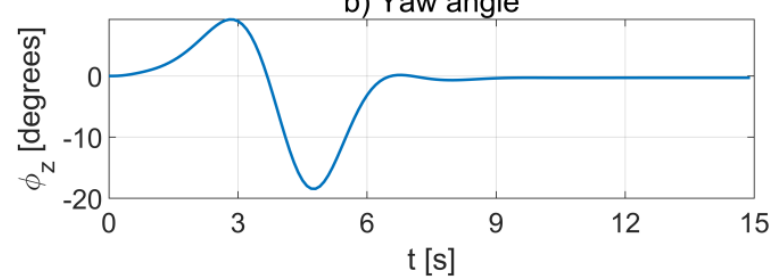

d) Curvature (inverse of radius of curvature)

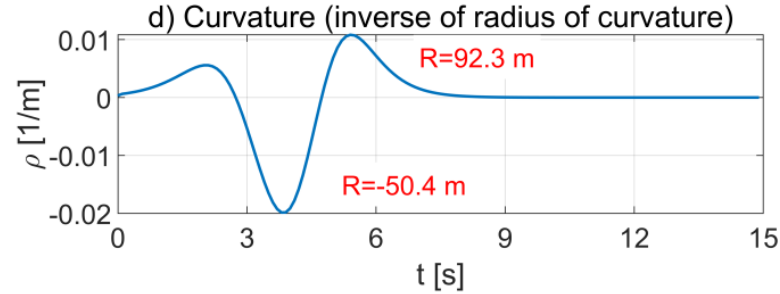

Fig. 4 Results obtained from the modeling of the lane keeping assistance system

\section{III.DOUBLE CHANGE OF TRAFFIC LANE}

The double change of the traffic lane represents the route for verifying the functioning of the electronic stability control system certified ISO 3888-2, route shown in fig. $5[1,10]$.

It is used to test the ability of cars to avoid fixed or mobile obstacles. In this test, the driver performs the following maneuvers: accelerates to the required speed; releases the accelerator pedal; turns to follow the route on the left lane; turns to return to the right lane. 


\section{International Advanced Research Journal in Science, Engineering and Technology}

Vol. 8, Issue 4, April 2021

\section{DOI: $10.17148 / I A R J S E T .2021 .8416$}

The test is considered successful if the driver and the car can perform the maneuver without hitting any of the cones located on the route that represent the limits of the lanes; these cones stand out at the bottom of fig. 5, which is the image of the tests performed with the Volkswagen Touareg 3.6 V6 FSI.
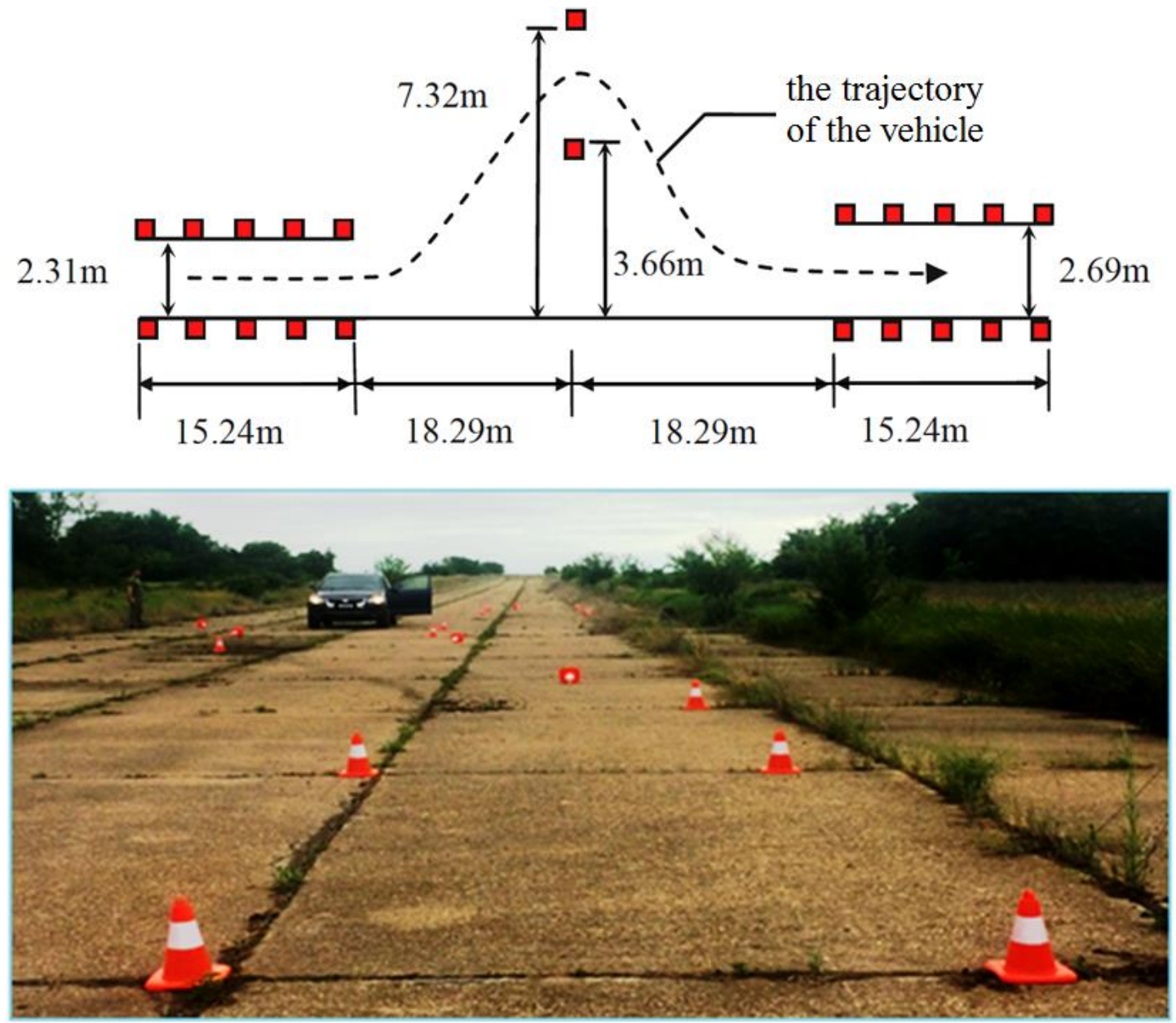

Fig. 5 Double lane change way according to ISO 3888-2

To simulate this test, use the Matlab software and the Simulink toolbox [8, 11, 18].

Thus, fig. 6 shows the diagram in Simulink for a car performing the double lane change over maneuver according to the diagram in fig. 5.

The application contains a block for the driver that generates the execution of the turn, acceleration and braking necessary to ensure the tracking of the required route (fig. 7).

As can be seen from the diagram shown in fig. 7, in this case a predictive model of the driver's action is used.

The controllers generate the engine torque, gearbox and ABS brake controls.

The car block contains the engine, controllers and 4-wheel body.

The graphical display block allows the graphical visualization of the functional parameters during the execution of the maneuver. 
DOI: $10.17148 /$ IARJSET.2021.8416

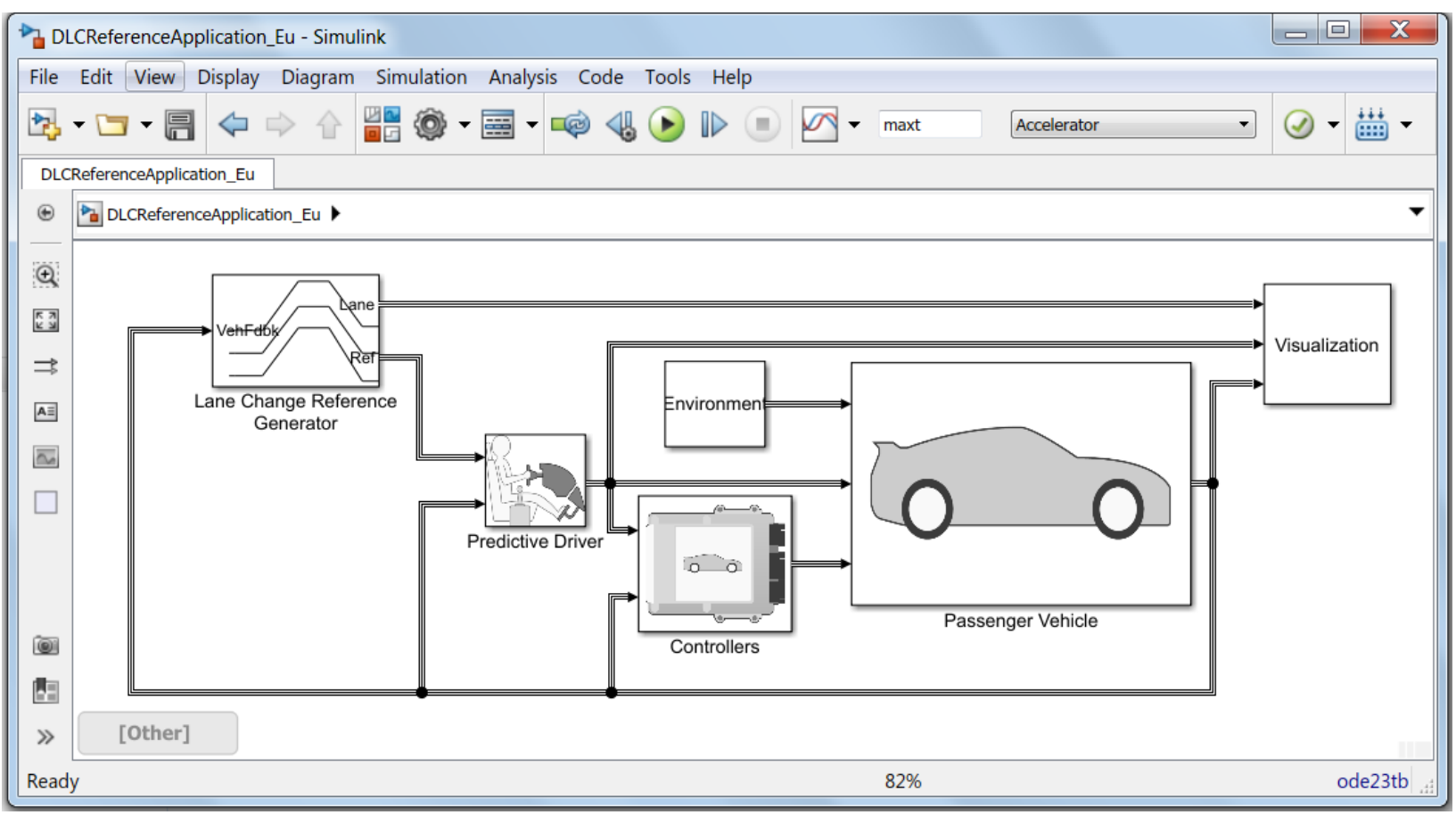

Fig. 6 Simulink Matlab modeling and simulation scheme [18]

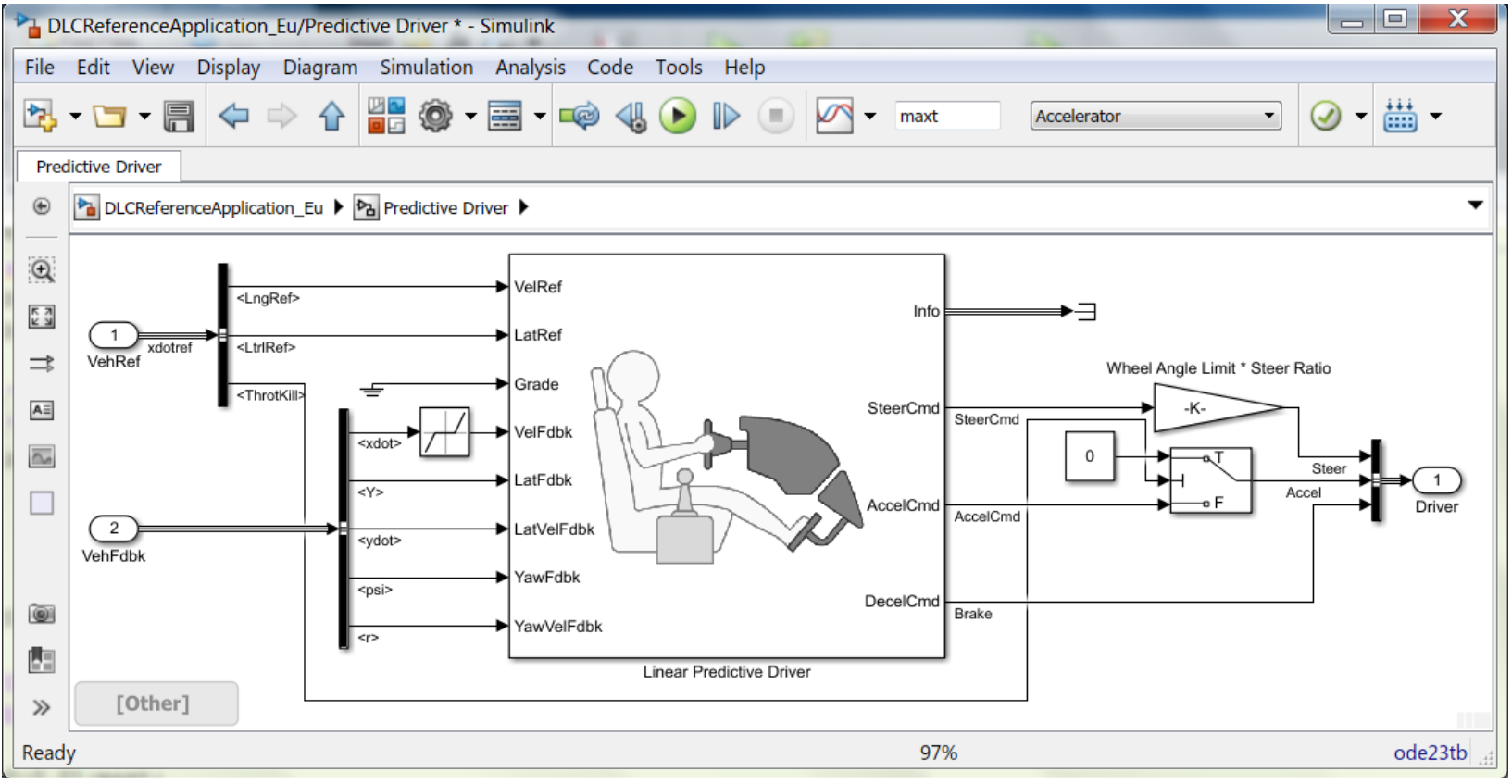

Fig. 7 Modeling and simulation of the driver's action [18]

Using the modeling diagrams in fig. 6 and fig. 7, the graphs with the variables shown in fig. 8 - fig. 11 are obtained. From these graphs it is found that the moment of starting the execution of the maneuver to change the lane is $t \approx 9 \mathrm{~s}$, for example from rotation of the steering wheel, as well as from the analysis of the graph of lateral acceleration and yaw angle or yaw rate.

The graph in fig. $8 \mathrm{~d}$ shows the existence of a direct non-linear dependence between the angle of rotation of the steering wheel $\delta_{v}$ and the lateral acceleration of the vehicle $a_{y}$; therefore, when the steering wheel angle increases, the lateral acceleration/deceleration of the vehicle also increases. 
DOI: $10.17148 /$ IARJSET.2021.8416

\section{Double lane change, some related functional variables}

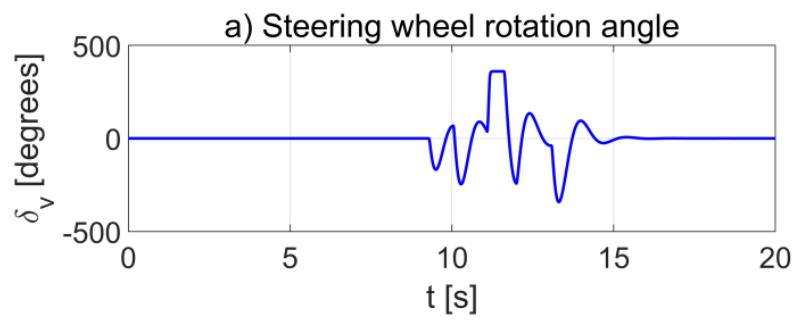

b) Lateral acceleration

c) Longitudinal speed
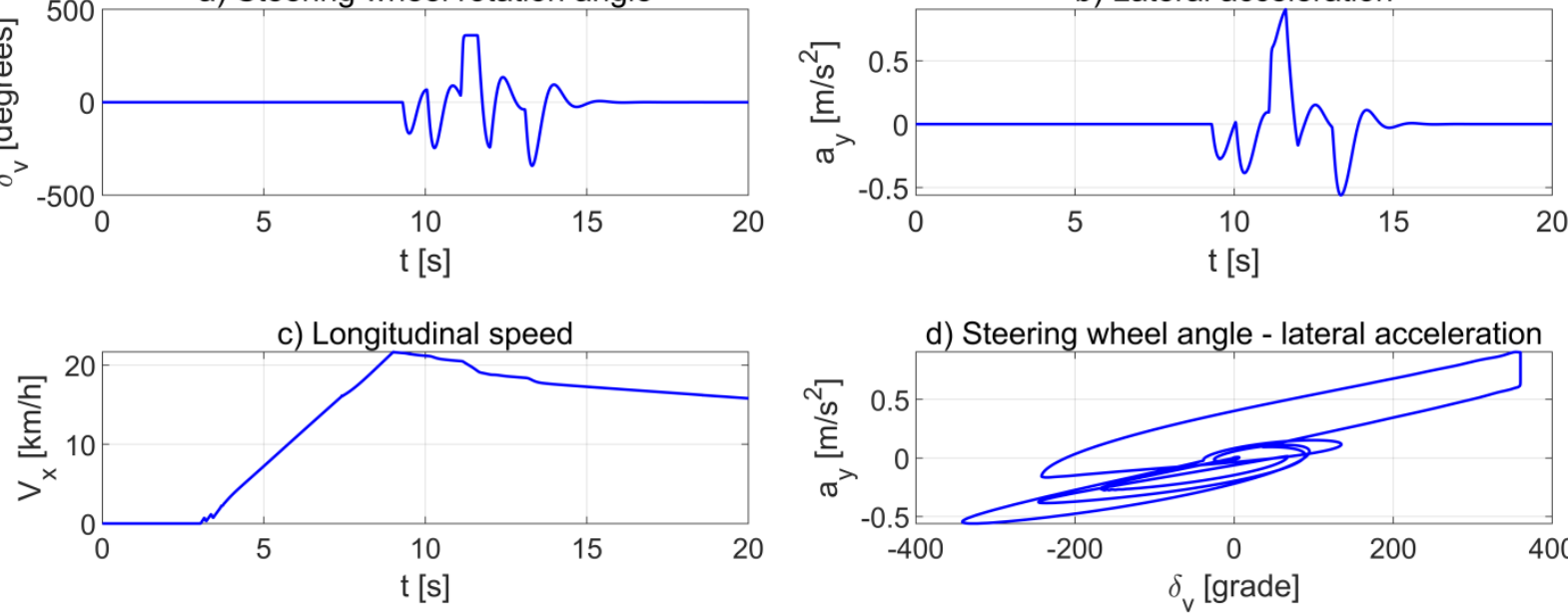

d) Steering wheel angle - lateral acceleration

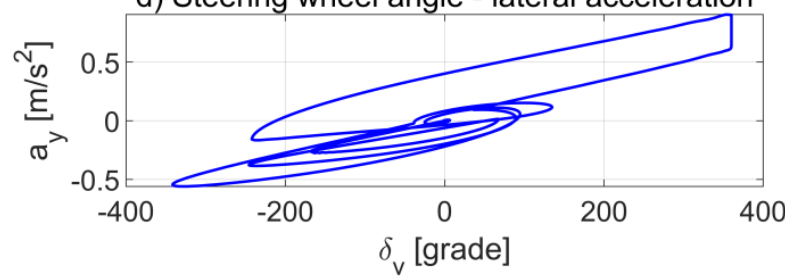

Fig. 8 Steering wheel angle, lateral acceleration and longitudinal speed

The graph in fig. 9c shows the same aspect mentioned above. Therefore, when the steering wheel angle increases, the yaw rate of the vehicle $\omega_{z}$ also increases. lane.

The negative and positive values of the yaw angle confirm a double change, in both directions, of the traffic

Fig. 9d shows the process of changing gears in the gearbox of the car.

\section{Double lane change, some related functional variables}
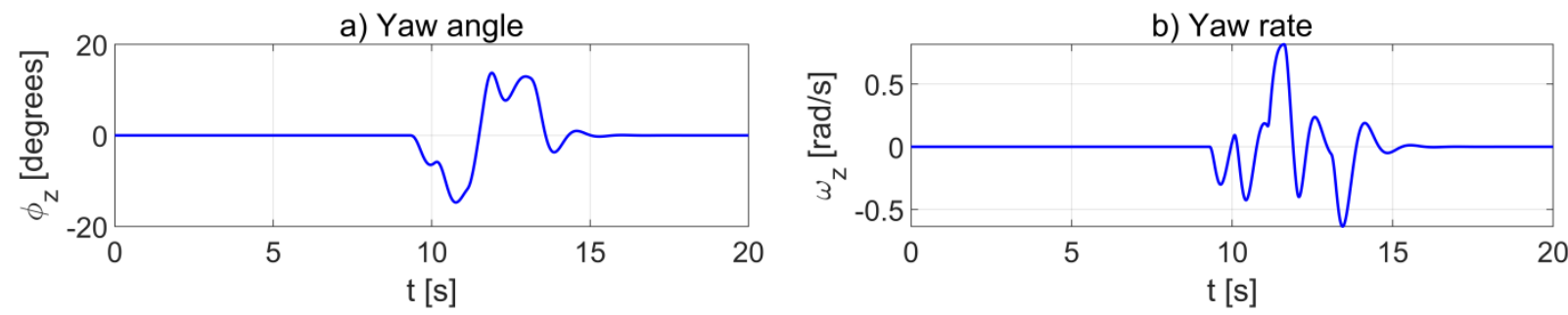

c) Steering wheel angle - yaw rate

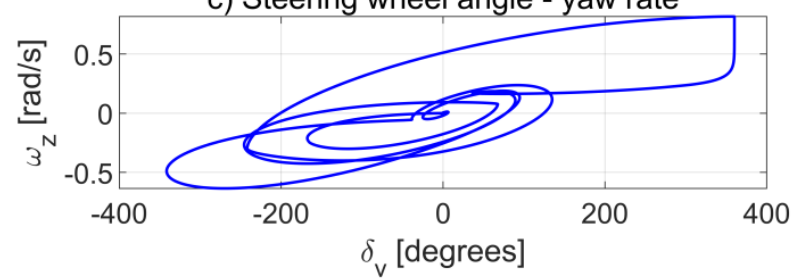

d) Gear ratio

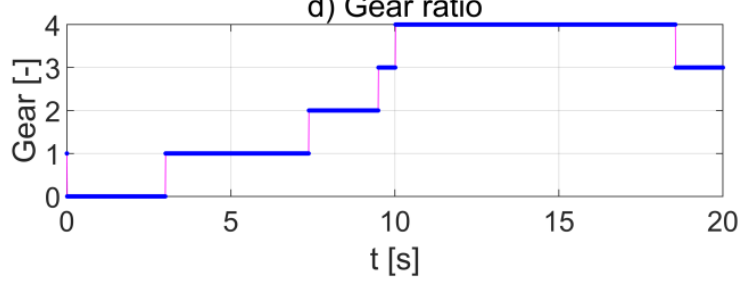

Fig. 9 Variations specific to the yaw motion and gears in the gearbox

Fig. 10 shows the values of the longitudinal distance and the lateral distance traveled by the car, as well as its trajectory.

Fig. 10b shows that at the end of the double lane change operation, the lateral distance returns to zero. 


\section{International Advanced Research Journal in Science, Engineering and Technology}

Vol. 8, Issue 4, April 2021

DOI: $10.17148 / I A R J S E T .2021 .8416$

Double lane change, some related functional variables
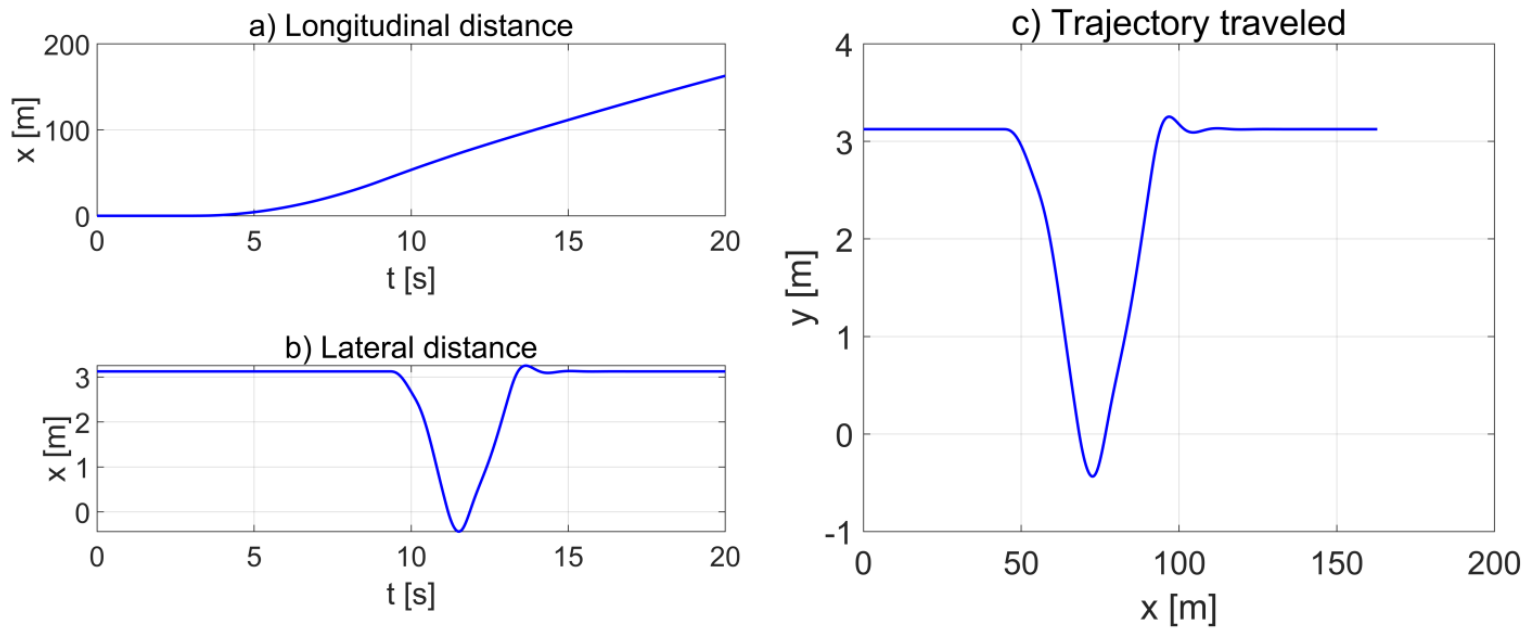

Fig. 10 Longitudinal distance, lateral distance and trajectory of the vehicle

From the analysis of the graph in fig. 11 it is found that the car has successfully passed the test of the double change of the traffic lane, its trajectory being within the desired limits and is close to the imposed trajectory between the two limits.

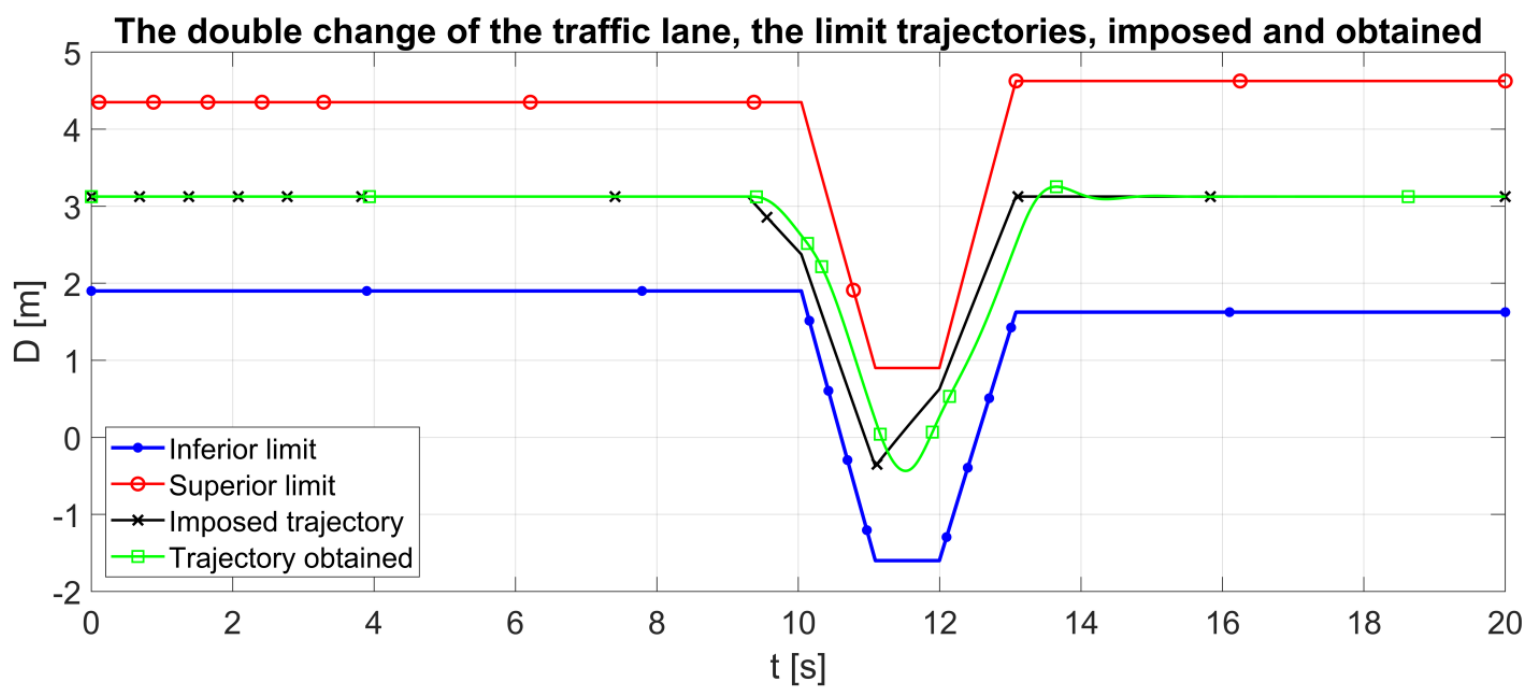

Fig. 11 The trajectories of the car at the double change of the lane

\section{IV.CONCLUSION}

Changing the lane is an important process, especially in congested traffic, as a wrong operation by the driver during this time can cause serious road accidents.

The lane keeping system must use, in this process, a chamber that measures the deviation at the lateral distance and the relative deviation of the turning angle of the car relative to the middle or a marginal side of the traffic lane.

The double change of the traffic lane represents the route of verifying the functioning of the electronic stability control system according to ISO 3888-2 certificate; in this respect, it should be noted that the electronic control algorithm of the ESC / ESP system with which the vehicle is equipped is of great importance [7, 17].

For the ESC to fulfill its role, the vehicle must be equipped with transducers for measuring longitudinal acceleration, lateral acceleration, yaw rate, wheel speed, steering angle and braking pressure.

In addition, on the basis of what is presented in the paper, it is important to establish the minimum safety distance that ensures the avoidance of road accidents. 


\section{International Advanced Research Journal in Science, Engineering and Technology}

Vol. 8, Issue 4, April 2021

\section{DOI: $10.17148 /$ IARJSET.2021.8416}

\section{REFERENCES}

[1]. S. Angelis, M. Tidlund, A. Leledakis, M. Lidberg, M. Nybacka and D. Katzourakis, ”Optimal Steering for Double-Lane Change Entry Speed Maximization", 12th International Symposium on Advanced Vehicle Control, AVEC '14, Sept. 2014, Tokyo, Japan

[2]. J. Bascunana, "Analysis of lane change crash avoidance", SAE paper 951895, 1995

[3]. M. Bin, "A study of lane-changing behavior model at weaving section considering conflicts", JEASTS, no. 5, pg. 2039-2052, 2003

[4]. H. Burg and A. Moser, "Handbook of accident reconstruction", Viewg\&Teubner, Kippenheim, Germany, 2013

[5]. T. Ding, "Research of safety lane change warning method based on potential angle collision point", JAT, vol. 10, pg. 1-24, 2019

[6]. G.M. Fitch, "Analysis of lane change crashes and near-crashes", NHTSA report, DOT HS 811147, 2009

[7]. W. Guoye, "Study of ESP control", International Conference of SSDMS, 2012

[8]. S. Hetrick, "Examination of driver lane change behavior", PhD thesis, State University, Blacksburg, 1997

[9]. H. Jula, "Collision Avoidance Analysis for Lane Changing and Merging", University of Southern California, 2007

[10]. E. Kutluay and H. Winner, "Assessment Methodology for Validation of Vehicle Dynamics Simulations Using Double Lane Change Maneuver", Proceedings of the 2012 Winter Simulation Conference, IEEE, 2012

[11]. S. Mammar, 'Time to line crossing for lane departure avoidance”, IEEE vol. 7, issue 2, pg. 226-241, 2006

[12]. S. Movidpour, "Modeling the lane changing execution", Monash University, 2010

[13]. E. Rossetter, "A potential field framework for active vehicle lanekeeping assistance", PhD thesis, Stanford University, 2003

[14]. K.B Vinoth, S. Abirami, R.B. Udhaya, L. Bharathia and R. Lohitha, "Detection and Content Retrieval of Object in an Image using YOLO”, International Advanced Research Journal in Science, Engineering and Technology (IARJSET), Vol. 6, Issue 6, June 2019, pg. 34-41

[15]. R.M. Stoica, VJ. Radulescu, D. Neagu, C. Trocan and I. Copae, “Aspects Regarding the Analysis and Reconstruction of Car Crashes", ROJAE, Volume 23, pg. 113, september 2017, ISSN 2457 - 5275 (Online, English), ISSN 1842 - 4074 (Print, Online, Romanian)

[16]. W. Xiaorui, "A lane change model with the consideration of car following behavior", SBS, no. 96, pg. 2354-2361, 2013

[17]. L. Zhao, "The optimization research on vehicle ESP control strategy", Applied Mechanics and materials, vol. 321-324, pg. 1548-1553, 2013

[18]. *** Automated Driving Toolbox, User's Guide, www.matworks.com, 2020 